\title{
Jurisprudentie
}

\section{De predispositie van de verdachte bij het stelen van een lokfiets: creëert de gelegenheid de dief?}

Noot bij HR 12 februari 2019 ECLI:NL:HR:2019:149

Mr. W. Albers*

\section{Inleiding}

1. Het is niet de eerste keer dat de vraag of de inzet van een lokfiets - een middel om personen die zich schuldig maken aan fietsendiefstal op heterdaad te kunnen aanhouden - rechtmatig is geschied, wordt voorgelegd aan ons hoogste rechtscollege. ${ }^{1}$ Volgens de bestendige rechtspraak van de Hoge Raad zijn opsporingsambtenaren op basis van de algemene taakstellende bepalingen - artikel 3 van de Politiewet 2012 en artikel $141 \mathrm{~Sv}$ - in beginsel bevoegd tot het inzetten van bepaalde lokmiddelen. Het plaatsen van een lokfiets is op zichzelf aldus niet ongeoorloofd, ook al steunt dit handelen niet op een specifieke wettelijke grondslag. ${ }^{2}$ De Hoge Raad heeft aan de inzet van lokmiddelen echter een beperkende voorwaarde gesteld. Dit is het zogeheten Tallon-criterium, dat - met de inwerkingtreding van de Wet bijzondere opsporingsbevoegdheden ${ }^{3}-$ is gecodificeerd voor de wettelijk geregelde opsporingsmetho-

* Mr. W. (Willemijn) Albers is docent Straf(proces)recht bij het Willem Pompe Instituut voor Strafrechtswetenschappen aan de Universiteit Utrecht.

1. Vgl. HR 28 oktober 2008, ECLI:NL:HR:2008:BE9817, NJ 2009/224; HR 23 januari 2018, ECLI:NL:HR:2018:62, NJ 2018/232, m.nt. N. Rozemond.

2. HR 28 oktober 2008, ECLI:NL:HR:2008:BE9817

3. Wet van 25 mei 1999, Stb. 1999, 245. den, zoals infiltratie en pseudokoop. ${ }^{4}$ Dit criterium strekt er onder andere toe om te voorkomen dat opsporingsambtenaren bepaalde vormen van criminaliteit uitlokken, om daar vervolgens repressief tegen op te treden. ${ }^{5}$ De verdachte mag door het optreden van de opsporingsambtenaar ingevolge dit criterium niet worden gebracht tot andere handelingen dan die waarop zijn opzet reeds van tevoren was gericht. ${ }^{6}$ Daarbij dienen ook de beginselen van proportionaliteit en subsidiariteit in acht te worden genomen. ${ }^{7}$ Strikt genomen dient de verdachte in het geval van de inzet van een lokfiets, nog vóór de feitelijke diefstal van de lokfiets opzet te hebben gehad op het stelen van een (willekeurige andere) fiets. Uit de meest recente jurisprudentie blijkt echter dat de wijze waarop dit criterium in concreto in de praktijk wordt toegepast, toch enige problemen met zich kan brengen. ${ }^{8}$
4. HR 4 december 1979, ECLI:NL:HR:1979:AB7429, NJ 1989/356 m.nt Th.W. van Veen.; HR 28 oktober 2008, ECLI:NL:HR:2008:BE9817; Kamerstukken I/ 1996/97, 25403, 3, p. 31.

5. G.J.M. Corstens, M.J. Borgers \& T. Kooijmans, Het Nederlands strafprocesrecht (negende druk), Deventer: Wolters Kluwer 2018, p. 544.

6. HR 4 december 1979, ECLI:NL:HR:1979:AB7429, NJ 1989/356 m.nt. Th.W. van Veen

7. HR 20 januari 2009, ECLI:NL:HR:2009:BF5603, NJ 2009/225, m.nt. M.J. Borgers, par. 3 en 4.; HR 6 oktober 2009, ECLI:NL:HR: 2009:BI7084, NJ 2009/503; HR 23 januari 2018, ECLI:NL:HR:2018:62, ro. 2.4 .

8. HR 23 januari 2018, ECLI:NL:HR:2018:62, NJ 2018/232, m.nt. K. Rozemond. 


\section{De feiten en het oordeel van de Hoge Raad}

2. In de onderhavige zaak heeft de politie, teneinde fietsendieven op te sporen, gebruikgemaakt van een als nieuw ogende witte lokfiets. Kenmerkend aan de positionering van de fiets, is het feit dat deze in afwijking van de andere fietsen in de omgeving niet met het voorwiel in het rek was geplaatst, maar op de standaard stond. De achterzijde van de fiets stak daardoor op zodanige wijze uit ten opzichte van andere fietsen in de omgeving, dat het voor passanten duidelijk zichtbaar was dat de sleutel nog in het slot stak. Op basis van deze vaststellingen stelt het hof dat het aannemelijk is dat de verdachte hierdoor een misdrijf heeft begaan, namelijk diefstal, waar zijn opzet niet van tevoren op was gericht. Hierbij wordt door het hof in aanmerking genomen dat de verdachte documentatie heeft, maar dat daaruit niet blijkt dat de verdachte zich de laatste jaren aan soortgelijke vermogensdelicten schuldig heeft gemaakt. Het hof stelt ook dat er evenmin andere aanwijzingen zijn waaruit het opzet van de verdachte op het plegen van vermogensdelicten blijkt. In het verlengde van de hiervoor beschreven argumentatie oordeelde het hof dan ook dat er in casu sprake was van uitlokking, hetgeen dient te leiden tot niet-ontvankelijkheid van het Openbaar Ministerie. Het cassatiemiddel, voorgesteld door het Openbaar Ministerie, behelst de klacht dat het oordeel van het hof - dat de verdachte door de manier waarop de lokfiets was geplaatst is uitgelokt tot het begaan van een misdrijf en dat dit moet leiden tot niet-ontvankelijkheid van het Openbaar Ministerie in de vervolging - blijk geeft van een onjuiste rechtsopvatting, dan wel ontoereikend is gemotiveerd. De conclusie van advocaat-generaal (hierna: A-G) Hofstee strekt tot vernietiging van de uitspraak en terugwijzing naar het hof. ${ }^{9}$ In diens conclusie verwijst A-G Hofstee naar de eerder angehaalde uitspraak van HR 23 januari 2018, ECLI:NL:HR:2018:62. In dit arrest was een soortgelijk geval aan de orde. De Hoge Raad overwoog in de zaak die leidde tot HR van 23 januari 2018, dat:

'De enkele omstandigheid dat het antreffen van de lokfiets de verdachte op het idee heeft gebracht deze lokfiets te stelen, maakt het plaatsen van deze fiets door de politie teneinde aldus personen die zich schuldig maken aan fietsendiefstal op heterdaad te kunnen betrappen, immers niet ongeoorloofd. ${ }^{10}$

Hierbij dient in aanmerking te worden genomen dat in de onderhavige zaak de lokfiets werd geplaatst in

9. CAG 13 november 2018, ECLI:NL:PHR:2018:1247, punt 13.

10. HR 23 januari 2018, ECLI:NL:HR:2018:6, r.o. 2.5.; CAG 13 november 2018; ECLI:NL:PHR:2018:1247, punt 10. een omgeving met andere fietsen. Hieruit volgt volgens A-G Hofstee dat de inzet van deze specifieke lokfiets de situatie ter plaatse niet wezenlijk heeft veranderd. ${ }^{11}$ In navolging van de conclusie van A-G Hofstee, casseert de Hoge Raad door aan het voorgaande toe te voegen dat:

'(...) aan de door het Hof vastgestelde omstandigheden wellicht kan worden ontleend dat het aantreffen van de lokfiets de verdachte op het idee heeft gebracht de fiets te stelen, maar niet dat verdachtes opzet niet reeds was gericht op het stelen van een fiets. ${ }^{12}$

\section{Creëert de gelegenheid de dief, of creëert de dief de gelegenheid?}

3. De problematiek rondom de inzet van lokmiddelen is niet onbeschreven gebleven de laatste jaren. ${ }^{13} \mathrm{De}$ onderhavige uitspraak van de Hoge Raad - en de lokmiddelen-jurisprudentie in bredere $\mathrm{zin}^{14}$ - roepen dan ook verschillende vragen op. Deze hebben onder andere betrekking op de wijze waarop het is toegestaan gebruik te maken van lokmiddelen in de opsporing van strafbare feiten en op de vraag welke invloed de inzet van deze middelen vervolgens kan hebben op de predispositie van verdachten.

Om deze vragen te kunnen beantwoorden, is het van belang een onderscheid te maken tussen de twee verschillende categorieën lokmiddelen, te weten: de inerte, ofwel niet-menselijke lokmiddelen, zoals een lokfiets of een lokauto, en de niet-inerte, ofwel menselijke lokmiddelen, zoals een lokoma of een lokpuber. ${ }^{15}$ Lokmiddelen kunnen namelijk op zeer uiteenlopende wijzen worden ingezet. Waar het ene lokmiddel of de opsporingsmethode zich meer richt tot een specifieke verdachte, richt een ander zich in beginsel tot een menigte. Bij dit onderscheid moet ook in aanmerking worden genomen dat de mate van interactie tussen de potentiële verdachte enerzijds en het inerte of niet-inerte lokmiddel anderzijds, sterk kan verschillen. Bij de inzet van een menselijk lokmiddel zal er, meer dan bij de inzet van een niet-menselijk lokmiddel, sneller een vorm van interactie plaatsvinden met de potentiële verdachte. ${ }^{16}$ Deze interactie kan vervolgens een groter risico op uitlokking tot het begaan van een strafbaar feit met zich brengen.

11. CAG 13 november 2018, ECLI:NL:PHR:2018:1247, punt 10; CAC 28 oktober 2008, ECLI:NL:PHR:2008:BE9817, punt 17.

12. HR 12 februari 2019, ECLI:NL:HR:2019:149, r.o. 2.5 .

13. Zie bijvoorbeeld L. Noyon, 'Inerte lokmiddelen en Tallon: over wanneer te nokken met lokken', TPWS 2018, p. 104-107

14. Zie o.a. HR 6 oktober 2009, ECLI:NL:HR:2009:BI7084, NJ 2009/503.

15. Noyon 2018, p. 104; HR 23 januari 2018, ECLI:NL:HR:2018:62.

16. Noyon 2018, p. 104; HR 6 februari 2018, ECLI:NL:HR:2018:155. 
Binnen de grenzen van het uitlokverbod is het eveneens relevant om een onderscheid te maken tussen de gerichte en ongerichte uitlokking. ${ }^{17}$ Zoals Rozemond in zijn annotatie onder HR 23 januari 2018 schreef, heeft de opsporingsambtenaar, indien hij of zij een uitlokkingshandeling direct op een specifiek persoon richt, de keuze gemaakt om een bepaald persoon te bewegen het strafbare feit te plegen. In die gevallen kan een rechtstreeks verband worden gelegd tussen de keuze van de opsporingsambtenaar voor een specifieke verdachte en het strafbare feit dat de verdachte vervolgens pleegt. ${ }^{18}$ Indien echter sprake is van ongerichte uitlokking, dan selecteert niet de opsporingsambtenaar de verdachte, maar de verdachte het (niet-) inerte lokmiddel, zonder dat daar - los van het plaatsen van het middel - verder een specifieke handeling van een opsporingsambtenaar aan te pas is gekomen. De verdachte heeft zichzelf geselecteerd, en is dus niet door een opsporingsambtenaar 'uitgekozen' uit een bepaalde groep mensen om vervolgens geheel autonoom te besluiten (in het specifieke geval van de lokfiets) de fiets te stelen. In de laatstgenoemde gevallen is het plaatsen van de fiets volgens Rozemond een noodzakelijke voorwaarde voor het begaan van het strafbare feit. De eigen keuze van de verdachte weegt in zijn ogen echter zwaarder in de causale keten die tot de diefstal heeft geleid. ${ }^{19}$ Aan de ene kant is deze benadering verdedigbaar door te stellen dat, indien je niet van plan bent om bijvoorbeeld een fiets of een auto(radio) etc. te stelen, je hier ook naar zou moeten handelen. Aan de andere kant lokt deze benadering de vraag uit in hoeverre de verdediging nog een kansrijk beroep kan doen op de rechtsbeschermende werking die het Tallon-criterium biedt.

Bestaat dan nooit een risico op uitlokking bij de inzet van inerte lokmiddelen en/of wanneer sprake is van ongerichte uitlokking? Mijns inziens is dit niet het geval. Het Tallon-criterium maakt niet voor niets onderdeel uit van het normatieve kader dat de inzet van (inerte) lokmiddelen begrenst. Of een bepaalde lokkende werking uitgaat van een inert lokmiddel, zoals een lokfiets, kan te maken hebben met de praktische invulling van de wijze waarop de fiets wordt ingezet. In dit verband kan bijvoorbeeld worden gedacht aan de wijze van plaatsen van de fiets, de wijk waarin de fiets wordt achtergelaten en hoe nieuw en opvallend de fiets is. Zoals A-G Hofstee in diens conclusie bij de onderhavige uitspraak stelde, zal mogelijk minder snel sprake zijn van uitlokking als de omgeving niet wezenlijk is veranderd, doordat de lokfiets wordt geplaatst tussen een grote

17. Zie bijv. Noyon 2018 , p. 104-105 en de annotatie van N. Rozemond onder HR 23 januari 2018, ECLI:NL:HR:2018:62, NJ 2018/232.

18. Zie de derde en vierde opmerking van $\mathrm{N}$. Rozemond onder HR 23 januari 2018, ECLI:NL:HR:2018:62, NJ 2018/232.

19. Zie de derde, vierde en vijfde opmerking van $N$. Rozemond onder $H R$ 23 januari 2018, ECLI:NL:HR:2018:62, NJ 2018/232. hoeveelheid andere fietsen. ${ }^{20}$ Indien de inzet en plaatsing van de lokfiets echter een significante afwijking met zich brengt ten opzichte van de bestaande situatie in de betreffende omgeving, kan het aannemelijk zijn dat de verdachte juist wel op het idee is gebracht om deze fiets te stelen. De vraag is echter wat nu precies moet worden verstaan onder een dergelijke significante afwijking. Hierover heeft de Hoge Raad zich nog niet nadrukkelijk uitgelaten, waardoor de kaders waarbinnen dergelijke lokmiddelen mogen worden ingezet vooralsnog niet geheel duidelijk zijn gegeven. De praktijk wijst echter uit dat betrekkelijk veel is toegestaan. ${ }^{21}$

\section{De predispositie van de verdachte}

4. De norm die het Tallon-criterium stelt met betrekking tot de predispositie van de verdachte is duidelijk. De verdachte mag niet zijn gebracht tot andere handelingen dan die waarop zijn opzet reeds tevoren was gericht. De inkleuring van deze norm heeft in de rechtspraak voornamelijk vorm gekregen in de context van de in de Wet bijzondere opsporingsbevoegdheden geregelde opsporingsbevoegdheden, zoals de eerdergenoemde infiltratie en pseudokoop. ${ }^{22}$ In deze gevallen zal de toetsing met betrekking tot de vraag of sprake is van uitlokking zich voornamelijk richten op het actieve handelen van opsporingsambtenaren aan de ene kant en de predispositie van de verdachte aan de andere kant. ${ }^{23}$ Bij de inzet van een inert lokmiddel zal echter niet snel sprake zijn van concreet actief handelen van een opsporingsambtenaar, waardoor een verdachte mogelijk kan worden uitgelokt. Het enige dat de opsporingsambtenaar feitelijk gezien doet, is het plaatsen van de lokfiets en vervolgens afwachten totdat een willekeurig persoon deze fiets steelt. Er is tot het moment van aanhouding geen sprake van direct contact met een verdachte. Bovendien is het in de meeste gevallen gecompliceerd om uit de feiten en omstandigheden op te maken of een verdachte vóór het stelen van de lokfiets een intentie had tot het verrichten van bepaalde criminele handelingen, nu er in eerste instantie in het geheel geen concrete verdachte in beeld is. Op basis van de hiervoor beschreven argumentatie concludeert Noyon dat de normatieve inkadering van het Tallon-criteri-

20. CAG 13 november 2018, ECLI:NL:PHR:2018:1247, punt 10. Zie bijvoorbeeld ook Hof Amsterdam 19 januari 2018, ECLI:NL:GHAMS: 2018:187; Hof Den Haag 8 februari 2016, ECLI:NL:GHDHA:2016:595.

21. Zie bijvoorbeeld HR 28 oktober 2008, ECLI:NL:HR:2008:BE9817; HR 6 oktober 2009, ECLI:NL:HR:2009:BI7084; HR 23 januari 2018, ECLI:NL:HR:2018:62.

22. Noyon 2018, p. 105.

23. Zie met betrekking tot deze afweging ter illustratie HR 6 februari 2018, ECLI:NL:HR:2018:155, NJ 2018/96. 
um bij inerte lokmiddelen mogelijk tekort kan schieten. ${ }^{24}$

Ook het door het Europees Hof voor de Rechten van de Mens (hierna: EHRM) in het licht van artikel 6 EVRM opgestelde normatieve kader heeft voornamelijk betrekking op het toetsen van de in essentie meer actieve undercoveroperaties. Dientengevolge is het dan ook te begrijpen dat het EHRM ter beantwoording van de vraag of sprake is van uitlokking eerder een relatief objectieve benadering kiest - die meer de nadruk legt op het optreden van de politie - dan de subjectieve benadering, waarbij het accent wordt gelegd op de intenties van de potentieel uitgelokte persoon. ${ }^{25}$ Het is aldus denkbaar dat het EHRM dit toetsingskader anders toepast in het geval van de inzet van passieve lokmiddelen. Het principe dat aan het uitlokverbod ten grondslag ligt, blijft in essentie echter hetzelfde. Bovendien vallen ook enkele subjectieve elementen te onderscheiden in het Straatsburgse kader. Om deze reden kan het mogelijk toch relevant zijn om een korte blik te werpen op het door het EHRM in onder andere Bannikova/Rusland uiteengezette toetsingskader. ${ }^{26}$

Uit de rechtspraak van het EHRM blijkt dat autoriteiten gebruik mogen maken van speciale (undercover) opsporingsmethoden, mits deze op zichzelf geen inbreuk maken op het recht op een eerlijk proces in de zin van artikel 6 EVRM. ${ }^{27}$ Een dergelijke opsporingsmethode kan - doordat de inzet ervan de verdachte bijvoorbeeld uitlokt tot het begaan van een bepaald strafbaar feit - een inbreuk maken op dit fundamentele recht op een eerlijk proces. Om deze reden stelt het EHRM dat uitlokking per definitie verboden is en dat ook publieke belangen het gebruik van middels uitlokking verkregen bewijs in een strafzaak niet kunnen rechtvaardigen. ${ }^{28}$ In dat verband benadrukt het EHRM dat het van belang is om het risico op uitlokking zoveel mogelijk te verkleinen, door de inzet van de risicovolle opsporingsmethoden op een duidelijke wijze te begrenzen en met waarborgen te omkleden. ${ }^{29}$

24. Noyon 2018, p. 105.

25. Zie het tweede randnummer van G. Knigge onder EHRM 9 juni 1998, NJ 2001/471 (Texeira de Castro/Portugal).

26. EHRM 4 november 2010, nr. 18757/06, EHRC 2011/9, m.nt. F.P. Ölçer (Bannikova/Rusland).

27. EHRM 5 februari 2008, nr. 74420/01, EHRC 2008/51 (Ramanauskas/ Litouwen), r.o. 51 en 53.

28. EHRM 4 november 2010, nr. 18757/06, EHRC 2011/9, m.nt. F.P. Ölçer (Bannikova/Rusland), r.o. 34; EHRM 5 februari 2008, nr. 74420/01, EHRC 2008/51 (Ramanauskas/Litouwen), r.o. 54.

29. EHRM 5 februari 2008, nr. 74420/01, EHRC 2008/51 (Ramanauskas/ Litouwen), r.o. 51. Het EHRM noemt - in EHRM 4 november 2010, nr. 18757/06, EHRC 2011/9, (Bannikova/Rusland), r.o 50 - in dit kader als voorbeeld het verlenen van toestemming voor de inzet van de opsporingsmethode door een rechter dan wel een officier van justitie. Het voorgaande is voor de gecodificeerde opsporingsmethoden - infiltratie en pseudokoop - als wettelijk vereiste opgenomen.
De ambtenaren die betrokken zijn bij de inzet van de opsporingsmethode dienen in overeenstemming met het verbod op uitlokking in wezen passief te handelen, om te voorkomen dat hun acties kunnen aanzetten tot, of invloed hebben op het plegen van een (nog ernstiger) strafbaar feit dan waar het opzet van de verdachte reeds op was gericht. ${ }^{30}$ De inzet van de methode zal dus in beginsel niet per definitie onrechtmatig zijn indien kan worden vastgesteld dat de verdachte het strafbare feit ook zou hebben gepleegd zonder tussenkomst van de opsporingsmethode. Het EHRM heeft, om toelaatbare inzet van opsporingsmethoden te kunnen onderscheiden van niet-toelaatbare inzet, in diens jurisprudentie het navolgende toetsingskader ontwikkeld.

Zoals kort hiervoor reeds is benadrukt behoort het optreden van de opsporende instanties volgens het EHRM essentially passive te zijn. ${ }^{31} \mathrm{Om}$ dit optreden inhoudelijk te kunnen beoordelen acht het EHRM de volgende factoren bepalend: 1) de redenen die ten grondslag liggen aan de operatie; 2) het gedrag van de uitvoerende autoriteiten; en in het bijzonder 3) of er een objectieve verdenking jegens de verdachte bestond van enige betrokkenheid bij strafbare feiten; 4) of dat de verdachte een predispositie had een strafbaar feit te plegen. ${ }^{32} \mathrm{Bij}$ de afweging van voornoemde factoren houdt het EHRM rekening met het feit of de verdachte wel of geen strafblad heeft. ${ }^{33}$ Volgens het EHRM is het enkele feit dat een verdachte eerder is veroordeeld voor het plegen van een strafbaar feit echter onvoldoende basis om aan te nemen dat de verdachte zich nog steeds bezighoudt met het ontplooien van criminele activiteiten. ${ }^{34}$ Een andere bepalende factor die ingevolge de rechtspraak van het EHRM moet worden meegewogen in de vaststelling of sprake is van uitlokking, betreft de vraag of de opsporingsambtenaren de verdachte onder druk hebben gezet om het strafbare feit te plegen. In dit kader is het onder andere van belang om te achterhalen van wie het initiatief tot het plegen van het strafbare feit uit is gegaan: de verdachte of de opsporingsambtenaar. ${ }^{35}$ Onder het nemen van een initiatief tot het plegen van een strafbaar feit worden ook de gevallen begrepen waarin de opsporingsambtenaar, ondanks een aanvankelijke weigering van de verdachte, herhaaldelijk heeft aangedrongen tot het plegen van het

30. EHRM 23 november 2017, nr. 47074/12 (GRBA/Kroatië), r.o. 99-101; EHRM 5 februari 2008, nr. 74420/01, EHRC 2008/51 (Ramanauskas/ Litouwen), r.o. 55.

31. EHRM 4 november 2010, nr. 18757/06, EHRC 2011/9, m.nt. F.P. Ölçer (Bannikova/Rusland), r.o. 38; EHRM 5 februari 2008, nr. 74420/01, EHRC 2008/51 (Ramanauskas/Litouwen), r.o. 55

32. EHRM 4 november 2010, nr. 18757/06, EHRC 2011/9, m.nt. F.P. Ölçer (Bannikova/Rusland), r.o. 38.

33. EHRM 9 juni 1998, nr. 44/1997/828/1034 (Teixeira de Castro/Portugal), r.o 37-38

34. EHRM 4 november 2010, nr. 18757/06, EHRC 2011/9, m.nt. F.P. Ölçer (Bannikova/Rusland), r.o. 41.

35. EHRM 5 februari 2008, nr. 74420/01, EHRC 2008/51 (Ramanauskas/ Litouwen), r.o 67 
feit. ${ }^{36}$ Het EHRM legt met betrekking tot alle voornoemde factoren de bewijslast bij de overheid. Het Openbaar Ministerie zal aldus moeten bewijzen dat er in een specifiek geval geen sprake was van uitlokking. ${ }^{37}$

Indien het EHRM in het kader van de hiervoor uiteengezette inhoudelijke toets tot de conclusie komt dat er mogelijk sprake is van niet-toelaatbare uitlokking, zal het Hof ook een procedurele toets uitvoeren. ${ }^{38}$ Deze toets komt er in het kort op neer dat het EHRM zal beoordelen of de nationale rechter op een adequate, transparante en zorgvuldige manier is omgegaan met het uitlokverweer én of de rechter vervolgens op een toereikende wijze rechtsgevolgen kan verbinden aan een vaststelling van uitlokking. ${ }^{39}$ De nationale procedure dient ingevolge de rechtspraak van het EHRM 'adversarial, thorough, comprehensive and conclusive' te zijn. ${ }^{40}$

Het valt niet te betwisten dat de inzet van een inert lokmiddel, zoals een lokfiets, in essentie zeer passief is. Over het algemeen zal bij de inzet van een dergelijk lokmiddel nog geen concrete verdachte in beeld zijn. Ook valt over het gedrag van de opsporingsambtenaren weinig anders op te merken dan dat zij de lokfiets onafgesloten en voorzien van een gpstracker hebben gestald op een plek waar veelvuldig fietsen worden gestolen. Mijns inziens is de kous daarmee echter nog niet af. Het zou te gemakkelijk zijn om de lokkende werking van de inzet van een inert lokmiddel en/of een lokmiddel waarvan een ongerichte uitlokking uitgaat op een dergelijke wijze weg te zetten. Op deze manier zou de predispositie van de verdachte slechts geen tot een zeer geringe rol van betekenis kunnen spelen bij de beantwoording van de vraag of er wel of niet sprake is van uitlokking. Dit terwijl uit de rechtspraak van het EHRM blijkt dat de predispositie van de verdachte wel een factor is die door een rechter dient te worden meegewogen bij het beoordelen van de vraag of er mogelijk sprake is van ontoelaatbare uitlokking.

$\mathrm{Nu}$ het optreden van de opsporingsambtenaren niet zozeer ter discussie staat is de crux voornamelijk gelegen in de wijze waarop invulling dient te worden gegeven aan het onderdeel van de norm waarin de predispositie van de verdachte verankerd is, te weten: of de verdachte wel of niet reeds van tevoren

36. EHRM 5 februari 2008, nr. 74420/01, EHRC 2008/51 (Ramanauskas/ Litouwen), r.o 67-68.

37. EHRM 4 november 2010, nr. 18757/06, EHRC 2011/9, m.nt. F.P. Ölçer (Bannikova/Rusland), r.o. 48; EHRM 29 september 2009, nrs. 23782/06 en 46629/06 (Constantin and Stoian/Roemenie), r.o. 53; EHRM 5 februari 2008, nr. 74420/01, EHRC 2008/51 (Ramanauskas/ Litouwen), r.o 70

38. EHRM 4 november 2010, nr. 18757/06, EHRC 2011/9, m.nt. F.P. Ölçer (Bannikova/Rusland), r.o. 54.

39. EHRM 4 november 2010, nr. 18757/06, EHRC 2011/9, m.nt. F.P. Ölçer (Bannikova/Rusland), r.o. 51-54.

40. EHRM 4 november 2010, nr. 18757/06, EHRC 2011/9, m.nt. F.P. Ölçer (Bannikova/Rusland), r.o. 57. opzet had op het plegen van een strafbaar feit. Als de norm strikt taalkundig wordt geinterpreteerd, dient de verdachte ingeval van de inzet van een lokfiets, vóór de diefstal van de lokfiets het opzet te hebben gehad op het stelen van een (willekeurige andere) fiets. Strekt de reikwijdte van het 'reeds van tevoren hebben van opzet' dan zo ver dat een potentiële verdachte bij het verlaten van zijn of haar huis al de intentie moet hebben gehad tot het stelen van een fiets? De vraag stellen is haar beantwoorden: een gemiddelde rechtsgetrouwe burger zal over het algemeen niet het voornemen hebben om een fiets te stelen in het geval deze op een 'presenteerblaadje' wordt aangeboden. De predispositie van verdachte hoeft dus niet zo ver van tevoren te zijn gericht op het stelen van een willekeurige fiets of het plegen van een vermogensdelict. Hoe kan de in het Talloncriterium vervatte norm dan worden uitgelegd? Uitgaande van de gemiddelde rechtsgetrouwe burger die gewoonlijk geen intentie heeft tot het plegen van vermogensdelicten - zal sprake zijn van ontoelaatbare uitlokking indien de inzet van het lokmiddel de situatie zo aantrekkelijk maakt dat deze burger alsnog overgaat tot het plegen van het strafbare feit. ${ }^{41}$ Het is evident dat in deze gevallen de door de politie gecreëerde gelegenheid de dief maakt. In dat verband blijkt uit de rechtspraak van zowel de Hoge Raad als het EHRM ook dat bij het beantwoorden van de vraag of in een specifiek geval sprake is van uitlokking, wordt meegewogen van wie het initiatief uitgaat tot het daadwerkelijk plegen van het strafbare feit. Indien het voornamelijk de opsporingsambtenaar is geweest die het initiatief heeft getoond tot het plegen van het feit, zal volgens voornoemde rechtspraak eerder sprake zijn van uitlokking.

\section{Afsluitende opmerkingen}

5. Terugkomend op de onderhavige zaak heeft de politie een nieuw ogende witte fiets, in een omgeving met andere fietsen, op zodanige wijze neergezet dat het duidelijk zichtbaar was dat de sleutel nog in het slot zat. Zoals beschreven kan het - met betrekking tot het evalueren van de uitlokkende werking van de lokfiets - van belang zijn om te beoordelen of de fiets een significante afwijking met zich brengt ten opzichte van de bestaande situatie in de omgeving. Dit hangt nauw samen met het hiervoor beschreven - door het handelen van de opsporingsambtenaren - creëren van een voor de gemiddelde rechtsgetrouwe burger aantrekkelijke situatie. Zoals gezegd is in de praktijk betrekkelijk veel toegestaan en kan uit de rechtspraak van de Hoge Raad niet zozeer worden opgemaakt wat onder een dergelijke significante afwijking moet worden verstaan. Desalniettemin ben ik van mening dat de plaatsing en het

41. Noyon 2018, p. 104-107. 
gebruik van de lokfiets in casu het gedrag van de verdachte niet wezenlijk zal hebben beinvloed.

Over de gehele linie ligt deze uitspraak in de lijn met de staande jurisprudentie van de Hoge Raad. Het is zoals gezegd echter niet de eerste keer dat de inzet van dit opsporingsmiddel ter discussie wordt gesteld. Kennelijk heerst toch nog onduidelijkheid met betrekking tot de vraag wanneer wel en wanneer er geen sprake is van uitlokking.

In de onderhavige uitspraak herhaalt de Hoge Raad de reeds bekende formule. Voor zover is er niets nieuws onder de zon. Wat ik echter wel opmerkelijk acht, is het aan het voorgaande door de Hoge Raad toegevoegde citaat:

'(..) aan de door het Hof vastgestelde omstandigheden wellicht kan worden ontleend dat het aantreffen van de lokfiets de verdachte op het idee heeft gebracht de fiets te stelen, maar niet dat verdachtes opzet niet reeds was gericht op het stelen van een fiets. ${ }^{42}$

Kan het opzet van de verdachte op het stelen van een fiets gelijk worden gesteld aan het, door het aantreffen van de lokfiets, op het idee gebracht worden van het stelen van de fiets? Door deze formule te gebruiken lijkt het bijna alsof het bestaan van een predispositie bij de verdachte wordt voorondersteld wanneer hij of zij de lokfiets steelt. Dit lijkt mij niet de gewenste benadering. Het gevolg hiervan is namelijk dat de verdediging, om (als dat in het geheel nog mogelijk is) een kansrijk beroep te kunnen doen op de bescherming van het Tallon-criterium, onomstotelijk dient te onderbouwen dat de verdachte van tevoren geen opzet had op het stelen van bijvoorbeeld een fiets, auto, buggy etc. Met andere woorden: op deze manier wordt de bewijslast om aan te tonen dat sprake is van uitlokking en in het verlengde daarvan de onschuld van de verdachte, voor een groot deel bij de verdediging neergelegd. Dit terwijl uit de uitlok-rechtspraak van het EHRM kan worden opgemaakt dat de bewijslast ten aanzien van de onder randnummer 4 genoemde Straatsburgse criteria - waaronder aldus ook de predispositie van de verdachte - bij de overheid dient te liggen. ${ }^{43}$ Het zou aldus aan de overheid moeten zijn om aan te tonen dat géén sprake was van uitlokking.

Het voornoemde citaat kan ook zo worden geïnterpreteerd dat de door de opsporingsambtenaren geplaatste fiets de verdachte wellicht op het idee heeft gebracht om deze fiets te stelen, maar dat het in de gegeven situatie niet aannemelijk is dat diens opzet niet reeds was gericht op het stelen van een fiets. Het is mogelijk dat de verdachte ver voor het aantreffen van de fiets nog geen opzet had op het stelen ervan, maar dat dit opzet bij de verdachte pas ontstond door het opmerken van de gelegenheid om deze fiets te kunnen stelen. Het initiatief tot het stelen van de fiets komt in dit geval geheel vanuit de verdachte zelf, nu naast het enkele plaatsen van de fiets geen andere (uitlokkings)handelingen zijn verricht door de opsporingsambtenaren. In het verlengde van het voorgaande kan worden beargumenteerd dat het opzet op het stelen van de fiets in deze gevallen niet op een onrechtmatige wijze door de politie is geinstigeerd. Het feit dat de door de opsporingsambtenaren - middels het plaatsen van de fiets - opgezette mogelijkheid het idee bij de verdachte heeft opgewekt, hoeft dat niet per definitie anders te maken. Het is immers de verdachte die ter plekke, zonder interventie van een opsporingsambtenaar, het initiatief toont om de fiets mee te nemen. Indien men in het kader van het uitlokverbod bij de rechtmatigheid van de inzet van inerte lokmiddelen de nadruk legt op de persoon vanuit wie het initiatief komt tot het plegen van het strafbare feit, kan aldus worden geconcludeerd dat - nu bij een dergelijke inzet zelden extra handelingen (anders dan het plaatsen van de fiets) van opsporingsambtenaren komen kijken - van uitlokking in de visie van de Hoge Raad niet snel sprake zal zijn.

Welke van de voornoemde interpretatiemogelijkheden men ook zou willen geven aan de invulling van het citaat, roept het voorgaande mijns inziens de vraag op of de bescherming die het Tallon-criterium bij de inzet van inerte lokmiddelen in beginsel biedt - met het oog op het beschermen van het recht op een eerlijk proces in de zin van artikel 6 EVRM - nog wel 'practical and effective'44 is.
44. EHRM 9 oktober 1979, nr. 6289/73 (Airey/lerland), r.o. 24; EHRM 22 september 1994, nr. 14862/89, ECLI:NL:HR:XX:1994:AD2160, NJ 1994/733 m.nt. G. Knigge (Lala/Nederland), r.o. 34 